\title{
Controllable preparation of highly active horseradish peroxidase-gold nanoparticle bionanoconjugate
}

\author{
Peng Zhang, Chunli Liu, Shanshan Song, Chifang Peng* \\ Jiangnan University, School of Food Science and Technology, State Key Lab of Food Science and Technology, Wuxi, Jiangsu, \\ 214122, PR China \\ "Corresponding author: pcf2125@yahoo.com.cn
}

\begin{abstract}
A novel method of immobilizing horse radish peroxidase enzyme (HRP) onto the surface of gold nanoparticles (GNPs) was developed. As a result, a high-activity bionanoconjugates was obtained through utilizing the biotin-streptavidin (SA) system. The HRP-SA-GNP bionanoconjugate with high activity was conveniently prepared through the biotin- avidin system. Compared with the HRP-GNP bioconjugate prepared through the traditional electrostatic absorption method, the enzyme activity per GNPs of this new bionanoconjugate was enhanced by 10 times. Moreover, the enzyme activity of this bionanoconjugate was controllable. The above method of bionanoconjugation preparation has promising applications in the fields including preparing highly active bio-nanoprobe and immobilized enzyme.
\end{abstract}

Keywords: horseradish peroxidase, gold nanoparticles, bionanoconjugate.

\section{INTRODUCTION}

Gold nanoparticles (GNPs), with outstanding optical and electric performance, have attracted great interest for many years, especially in biosensors ${ }^{1-3}$ and biocatalysis $^{4}$. The GNPs loaded with biological molecules with a specific recognition function (antibody, oligonucleotide and enzyme) $)^{5-9}$ can be used to construct high sensitivity of biosensors. Among them, the method of immobilizing enzyme molecules on the surface of GNPs plays a very important role. The characteristics of enzyme molecule can be effectively enhanced by conjugating with nanoparticles, which will bring a significant benefit in biosensors and enzyme catalytic reaction. By virtue of high biocompatibility, gold nanoparticles can be used as an excellent protein carrier. Immobilizing protein molecules on the surface of GNPs via electrostatic adsorption is a simple and facile method and has been applied widely. However, there are also some drawbacks of this protein immobilization method. After protein absorbed onto the surface of GNPs via electrostatic interaction, the conformation of protein molecules will change to some degree and these molecules are randomly arranged on the surface of GNPs. During this immobilization, the activity center of some enzyme molecules will be inactive or covered, which significantly reduces the activity of an enzyme on the surface of GNPs. For example, Pandey, and $\mathrm{Li}^{10-11}$ coated GNPs with thioalkyl acid and coupled these GNPs and glucose oxidase by EDC/NHS. Their results showed that the activity of GOD can be kept well and the thermal stability of GOD will be visibly improved. Considering that GNPs precipitation often happens when immobilizing an enzyme on the GNPs surface by this EDC methods, Chirra et al ${ }^{12}$ compared two procedures of coupling enzyme catalase with GNPs. In the first method, they utilized EDC/NHS to conjugate the thioalkyl acid-coated GNPs with catalase. In the second method, taking advantage of the high affinity between biotin and streptavidin, after biotinylation GNPs and catalase were coupled using streptavidin as a crosslinker. Their results showed that biotin-streptavidin catalase-GNPs conjugate was exhibited as more stable and was smaller than that obtained by the carbodiimide chemistry approach. It should also be noted that the catalase activity of this catalase-GNPs showed no loss of enymatic activity. Therefore, the biotin-streptavidin based enzyme-GNPs conjugate preparation approach was a valuable strategy for developing new protein-GNPs bionanoconjugates. However, this biotin-streptavidin based method needs a very rare reagent (biotin-HPDP) and is tedious, which hinders its wide application. Thus, it is necessary to further research how to apply biotinstreptavidin more effectively to prepare the enzyme-GNP conjugate. This paper developed a simpler method, by two steps, to immobilize horseradish peroxidase (HRP) on the GNPs surface via the biotin-streptavidin system. The prepared bionanoconjugate has the advantages of high monodispersion and enzyme activity.

\section{EXPERIMENTAL}

\section{Materials}

Chloroauric acid, trisodium citrate,streptavidin (SA) and biotin-N-hydroxyl-succinicimide (BNHS) were obtained from Sigma-Aldrich (Shanghai, China). Horse radish peroxide enzyme (HRP, 250u/mg) was purchased from Sangon Biotech Co, Ltd. (Shanghai, China). All other reagents were of analytical grade and from Shanghai Chemical Reagents Company (Shanghai, China). Aqueous solutions used in all of the experiments were prepared using the Milli-Q water by Milli-Q system (Millipore, Bedford, MA).

\section{Biotinylation of HRP}

The biotinylation of catalase was carried out using succinimide chemistry. Briefly, $80 \mu \mathrm{L}$ biotin-N-hydroxysuccinimide (BNHS) (Sigma) at $25 \mathrm{mg} / \mathrm{ml}$ in DMSO was added to a $2 \mathrm{mg} / \mathrm{ml}$ HRP solution in phosphate buffer (PB, $0.01 \mathrm{M}, \mathrm{pH} 8.0$,). The mixture was shaken slowly at room temperature for $2 \mathrm{~h}$, after which $10 \mu \mathrm{L}$ of $16.4 \mathrm{M}$ ethanolamine was added to stop the reaction by reacting with any free BNHS. The biotinylated HRP was dialyzed against phosphate buffer $(0.01 \mathrm{M}, \mathrm{pH} 7.4)$ for 3 days, with three buffer changes a day. 


\section{The preparation of gold nanoparticles}

GNPs were prepared using the trisodium citrate reduction method. Briefly, $100 \mathrm{~mL}$ of $0.1 \%$ chloroauric acid was added into a flask washed by aqua regia and boiled under stirring. To this solution, $2 \mathrm{~mL}$ of $1 \%$ trisodium citrate was added dropwise. The solution was kept boiling for $20 \mathrm{~min}$, after which it turned to the red wine colour. The absorption spectrum of this GNPs solution was tested. From the UV-vis spectrum of GNP, the average particle size was evaluated to be about $16 \mathrm{~nm}$ and the concentration of GNPs was calculated to be $2 \mathrm{nmol} / \mathrm{L}^{13}$.

\section{The preparation of HRP-GNP conjugate}

\section{The preparation of SA-GNP conjugate}

After GNPs solutions were adjusted to varied $\mathrm{pH}$ value by $\mathrm{K}_{2} \mathrm{CO}_{3}$ solution, some streptavidin (SA) was mixed with them. To $1 \mathrm{~mL}$ of $2 \mathrm{nmol} / \mathrm{L}$ GNPs solutions, $0,1,2$ or $3 \mu \mathrm{L} \mathrm{K}_{2} \mathrm{CO}_{3}$ solution $(1 \%, \mathrm{~m} / \mathrm{m})$ was added, then 100 $\mu \mathrm{L}$ of SA $(0.1$ or $0.2 \mathrm{mg} / \mathrm{mL})$ was added to the above mixtures. After shaking for $30 \mathrm{~min}(500 \mathrm{rpm})$ under room temperature, the mixtures stood at $4{ }^{\circ} \mathrm{C}$ for $24 \mathrm{~h}$. The mixture, which seemed no color change visually, was selected and evaluated the absorption spectrum ranging from 400 800 nm. Finally, the prepared SA-GNP when $0.1 \mathrm{mg} / \mathrm{mL}$ streptavidin and $2 \mu \mathrm{L} \mathrm{K}_{2} \mathrm{CO}_{3}$ was applied to further preparation.

\section{The preparation of HRP-SA-GNP conjugate}

The above SA-GNPs conjugate was centrifuged at $12000 \mathrm{rpm}$ (centrifuge 5415R, Eppendorf ) for $15 \mathrm{~min}$. After the supernatant was discarded, the obtained pellet was dispersed into $1 \mathrm{~mL}$ of $0.01 \mathrm{M}$ phosphate buffer (PB). After the above centrifugation was repeated three times, $100 \mu \mathrm{L}$ of Bio-HRP $(0.2 \mathrm{mg} / \mathrm{mL}, 1.0 \mathrm{mg} / \mathrm{mL}$ or $2.0 \mathrm{mg} / \mathrm{mL}$ ) or $200 \mu \mathrm{L}$ of $2.0 \mathrm{mg} / \mathrm{mL}$ Bio-HRP was added to the purified SA-GNPs conjugate. The mixtures were vortexed, shaken at room temperature for $30 \mathrm{~min}$ and then dialyzed against $2 \mathrm{~L} \mathrm{~PB}(0.01 \mathrm{M}, \mathrm{pH} 7.4)$ at $4{ }^{\circ} \mathrm{C}$ for 2 days by changing buffer three times a day.

\section{The identification of nanoparticles and bionanoconjugates}

The absorption spectrum of GNPs, SA-GNPs and HRP-SA-GNPs, ranging from $400 \sim 800 \mathrm{~nm}$, were tested (BioMate 6 Spectrophotometer, Thermo). The particle size of the three samples was analyzed with dynamics laser scattering (DLS) (Zetasizer Nano ZS, Malvern) and each sample were tested three times. The average particle size obtained were the hydrate sizes of the samples. The transmission electron microscopy images (TEM) (JEM2100, JEOL) of three samples on carbon grids were taken by operating at $20 \mathrm{kV}$.

\section{Analysis of enzyme activity}

To a cuvette, $200 \mu \mathrm{L}$ of fresh HRP substrate solution (50 mmol/L sodium citrate buffer $(\mathrm{pH} 5.0)$ containing $0.01 \%(\mathrm{w} / \mathrm{v})$ TMB and $0.005 \%(\mathrm{v} / \mathrm{v}) \mathrm{H}_{2} \mathrm{O}_{2}$ ) was added and mixed quickly with $300 \mu \mathrm{L}$ of $10 \mathrm{ng} / \mathrm{mL}$ HRP solution (0.01M PB, pH7.4). The absorption values at 650 $\mathrm{nm}$ were recorded for $5 \mathrm{~min}$ with $10 \mathrm{~s}$ intervals. The bionanoconjugates of HRP and GNPs were diluted with $0.01 \mathrm{M}$ PB ( $\mathrm{pH} 7.4)$ and then reacted with the enzyme substrate in the same way. The absorption values at 1 min were regarded as the enzyme activity of HRP-GNPs.

\section{RESULTS AND DISCUSSION}

\section{Analysis of biotinylation of HRP}

\section{UV-visible spectrum of Bio-HRP}

After HRP was biotinylated, the shoulder peak of it, ranging from $250 \sim 280 \mathrm{~nm}$, became a ramp and the ratio of absorption value at $280 \mathrm{~nm}$ to that at $403 \mathrm{~nm}$ increased by $33 \%$, from 0.33 (HRP) to 0.44 (Bio-HRP) (Figure 1). These obvious changes came from the maximum absorption peak of biotin at about $260 \mathrm{~nm}$. The results proved that HRP was successfully biotinylated.

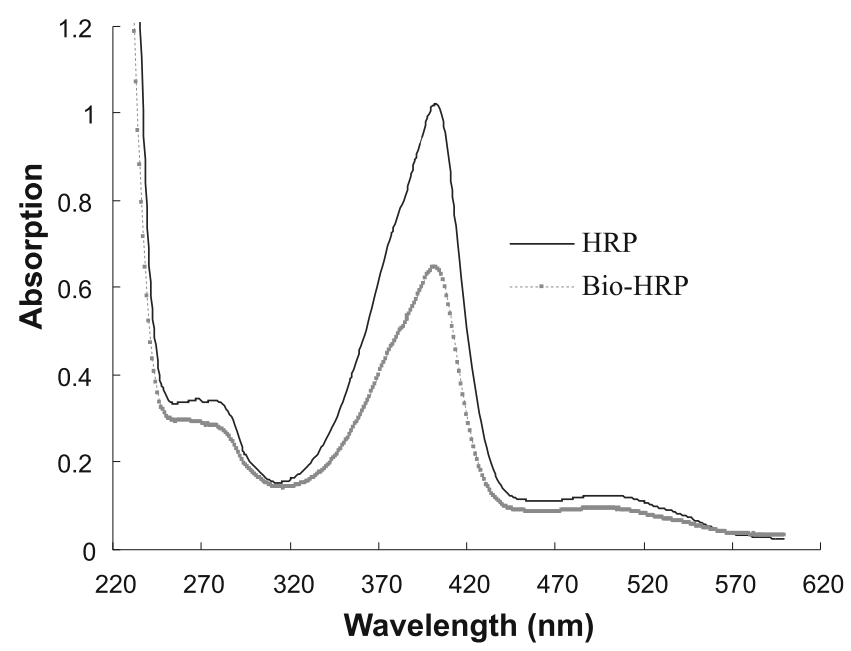

Figure 1. UV-visible spectrum of HRP and Bio-HRP. The concentrations of HRP and Bio-HRP were $0.6 \mathrm{mg} / \mathrm{L}$ and $0.36 \mathrm{mg} / \mathrm{L}$, respectively

\section{Analysis of enzyme activity}

From the catalytic reaction curves of HRP and Bio-HRP, it was shown that the reaction velocity of Bio-HRP was the same as that of HRP within $2 \mathrm{~min}$, although a small difference can be seen after 2 min in the curve (Figure2). The slight difference may come from the structure change of HRP. Since the above biotinylated modification proceeded randomly, biotin will probably bind with amino residues near the active centre of enzyme molecule.

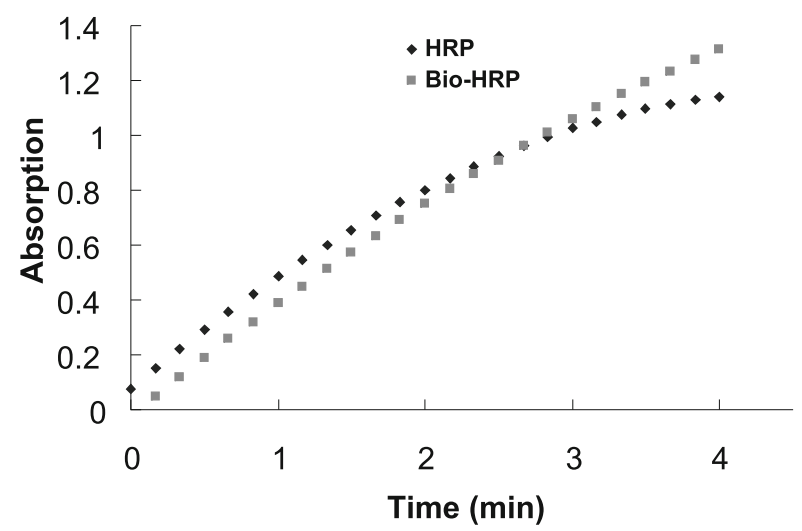

Figure 2. The catalytic reaction curves of HRP and Bio-HRP. Enzyme concentrations both were $10 \mathrm{ng} / \mathrm{mL}$ 
2.2 The identification of HRP-SA-GNPs biological conjugate

\section{The analysis of absorption spectrum.}

The maximum absorption peak $\left(\lambda_{\mathrm{m}}\right)$ of the prepared GNPs was at $518 \mathrm{~nm}$ (Figure 3). After being coated with $\mathrm{SA}$, the $\lambda_{\mathrm{m}}$ of SA-GNPs increased by $10 \mathrm{~nm}$ and was red-shifted to $528 \mathrm{~nm}$. This result is consistent with that the plasma resonance absorption of GNPs increases as its particle size increases in a certain range. However, the $\lambda_{\mathrm{m}}$ didn't rise any more after Bio-HRP combined with SA on the surface of GNPs. These results demonstrated that the influence of protein coating on the plasma resonance absorption of GNPs was limited. Note that GNP, SA-GNP and HRP-SA-GNP prepared here were all mono-dispersed concluded from the featured peaks of SA-GNP and HRP-SA-GNP had the same shape as the GNPs. And these were also demonstrated on TEM images (Figure 4).

Analysis of the size distribution of protein-GNP conjugates

Analysis of the size distribution of GNPs, SA-GNP and HRP-SA-GNP with DLS showed that the average hydration sizes of GNPs, SA-GNP and HRP-SA-GNP were $17.6 \mathrm{~nm}, 26 \mathrm{~nm}$ and $32.3 \mathrm{~nm}$, respectively (Figure 4).

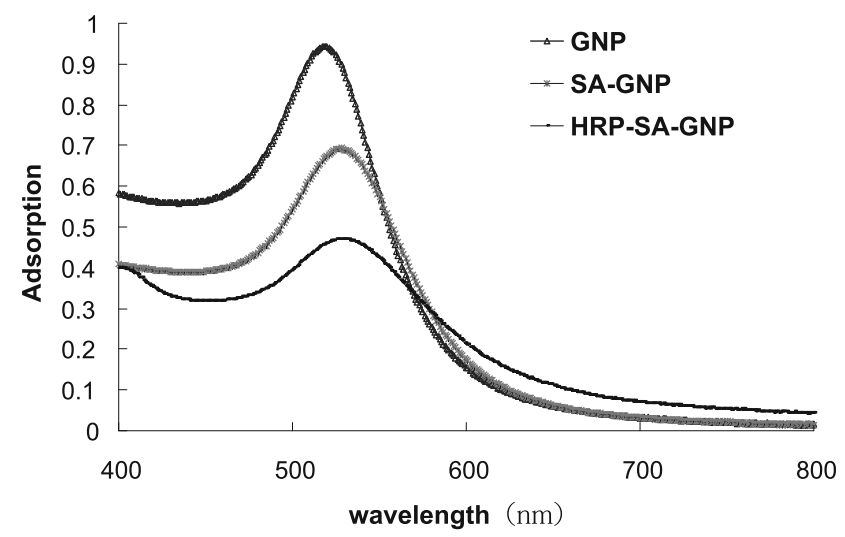

Figure 3. UV-vis spectrum of GNP and protein-GNP conjugates. The concentration of Bio-HRP was $1 \mathrm{mg} / \mathrm{mL}$ used for preparing HRP-SA-GNP

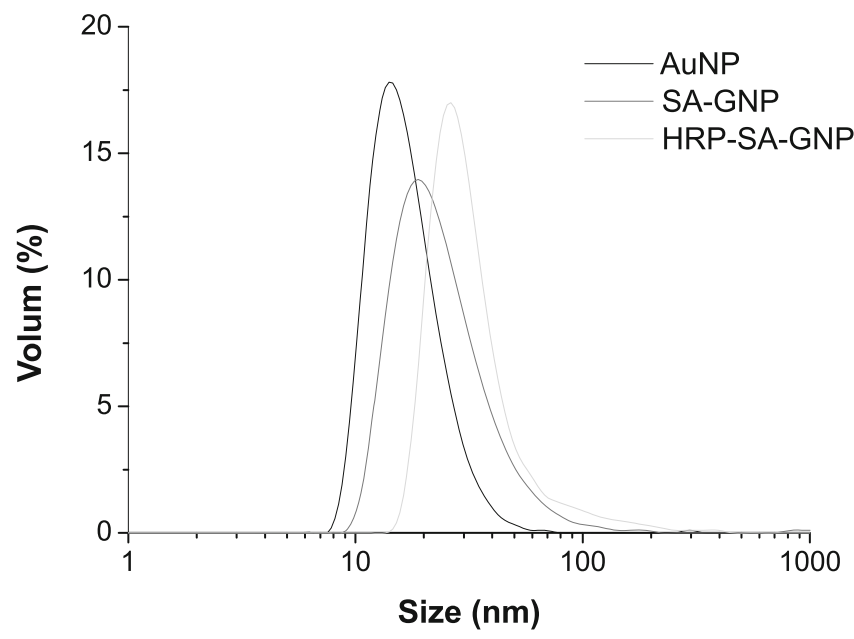

Figure 5. The particle size distribution of GNP and proteinGNP conjugates

When comparing GNPs with SA-GNP, the particle size increased $8.4 \mathrm{~nm}$, from which the hydration size of SA was deduced to be $4.2 \mathrm{~nm}$. This size is similar to the hydration size of free SA molecule. Comparing SA-GNP with HRP-SA-GNP, the particle size increased $6.3 \mathrm{~nm}$, which was also consistent with the size of free HRP molecule. The above changes in size demonstrated that SA and Bio-HRP have combined stably with GNPs.

\section{Enzyme activity of enzyme-GNP conjugates}

To the as-prepared SA-GNP conjugate, varied final concentration of Bio-HRP $(0.02,0.1$ or $0.2 \mathrm{mg} / \mathrm{mL})$ was added. The enzyme activities of three HRP-SA-GNP conjugates obtained were analyzed. It was found that the enzyme activity of HRP-SA-GNP conjugate increased as the final concentration of the Bio-HRP increased in the range of $0.02 \sim 0.2 \mathrm{mg} / \mathrm{mL}$ and then saturated at higher Bio-HRP concentration (Table 1). The result also showed that the amount of HRP combined onto the GNP surface was controllable to some extent in this bionanoconjugate fabrication. HRP-GNP conjugate via electrostatic adsorption of HRP onto the GNP surface was also prepared with adding the same or higher con-

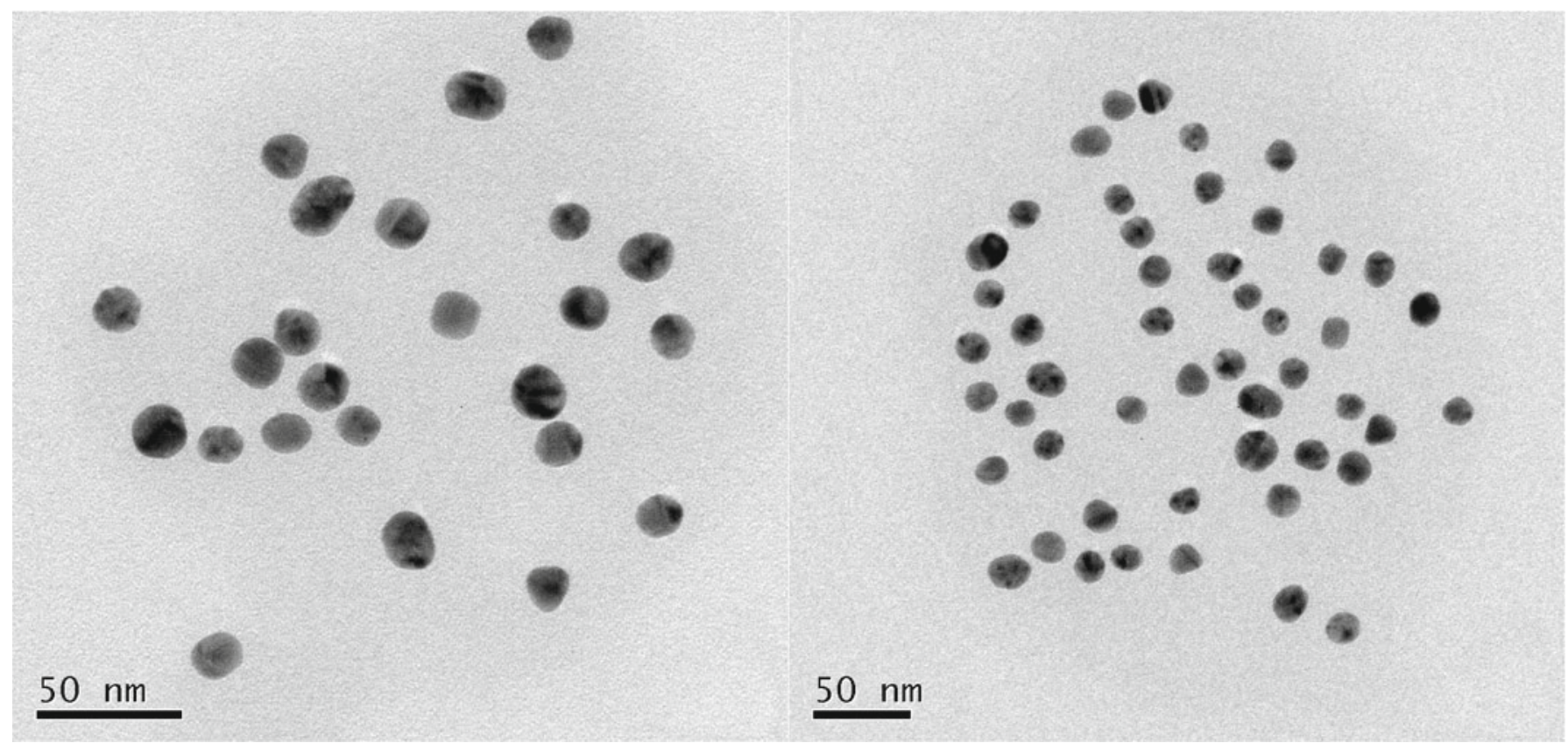

Figure 4. TEM images of GNPs (a) and HRP-SA-GNP conjugate (b) 
Table 1. Activity of enzyme-GNP conjugates increased with increasing concentration of Bio-HRP for HRP-SAGNP preparation

\begin{tabular}{|l|c|c|c|}
\hline $\begin{array}{l}\text { The final } \\
\text { concentration of } \\
\begin{array}{l}\text { Bio-HRP } \\
(\mathrm{mg} / \mathrm{mL})\end{array}\end{array}$ & $\begin{array}{c}\text { HRP-SA- } \\
\text { GNP } \\
(\mathrm{mU} / \mathrm{nmol} \\
\mathrm{GNP})\end{array}$ & $\begin{array}{c}\text { The final } \\
\text { concentration } \\
\text { of HRP } \\
(\mathrm{mg} / \mathrm{mL})\end{array}$ & $\begin{array}{c}\text { HRP- } \\
\text { GNP } \\
(\mathrm{mU} / \\
\mathrm{nmol} \\
\mathrm{GNP})\end{array}$ \\
\hline 0.02 & 0.7 & 0.02 & 0.21 \\
\hline 0.1 & 2.7 & 0.1 & 0.52 \\
\hline 0.2 & 5.7 & 0.2 & 0.55 \\
\hline 0.4 & 6.0 & 0.4 & 0.58 \\
\hline
\end{tabular}

centration HRP. Comparing the conjugates with highest enzyme active prepared by two approaches, it was found that the enzyme activity of HRP-SA-GNP was 10 times higher than that of HRP-GNP conjugate (Table 1).

\section{CONCLUSIONS}

A simple route of preparing a novel HRP-SA-GNP bionanoconjugate has been demonstrated. The enzyme activity of bionanoconjugate was adjustable through the control of the loading amount of HRP on the surface of GNPs and can achieve the activity which is 10 times as high as that of traditional HRP-GNP bionanoconjugate. By preparing biotinylated antibody or antigen, this bionanoconjugate can be developed further into bionano-labels for ultrasensitive biosensors. The enzyme immobilization approach can also be applied to other enzyme nano-carriers preparations.

\section{Acknowledgements}

This work was partly supported by the new faculty fund of Research Program of Sate Key Laboratory of Food Science and Technology, Jiangnan University (SKLF-ZZA-201202) and the foundation for the author of national excellent doctoral dissertation of China (No. 201187).

\section{LITERATURE CITED}

1. Xiao, Y., Patolsky, F., Katz, E. , Hainfeld, J.F., \& Willner, I. (2003). Plugging into enzymes: nanowiring of redox enzymes by a gold nanoparticle, Science, 299, 1877-1881. DOI: 10.1126/science.1080664.

2. Liu, T., Tang, J., \& Jiang, L. (2004). The enhancement effect of gold nanoparticles as a surface modifier on DNA sensor sensitivity, Biochemical and Biophysical Research Communications, 313, 3-7. DOI: 10.1016/j. bbrc.2003.11.098.

3. Cheng, Y., Pun, C., Tsai, C., \& Chen, P. (2005). An array-based CMOS biochip for electrical detection of DNA with multilayer self-assembly gold nanoparticles, Sensor and Actuator B, 109, 249-255. DOI: 10.1016/j. snb.2004.12.072.

4. Pasquato, L., Pengo, P., \& Scrimin, P. (2004). Functional gold nanoparticles for recognition and catalysis, Jouranl of materials Chemistry, 14, 3481-3487. DOI: 10.1039/B410476E.

5. Ambrosi, A., Airo, F., \& Merkoci, A. (2010). Enhanced Gold Nanoparticle Based ELISA for a Breast Cancer Biomarker. Analytical Chemistry, 82, 1151-1156. DOI: $10.1021 / \mathrm{ac} 902492 \mathrm{c}$.
6. Jia, C.P., Zhong, X.Q., Hua, B., Liu, M.Y., Jing, F.X., Lou, X.H., Yao, S.H., Xiang, J. Q., Jin, Q.H., \& Zhao, J.L. (2009). Nano-ELISA for highly sensitive protein detection. Biosensors and Bioelectronics, 24, 2836-2841. DOI: 10.1016/j.bios.2009.02.024.

7. Zhou, Y., Tian, X.L., Li, Y.S., Pan, F.G., Zhang, Y.Y., Zhang, Yang, L., Wang, X.R., Ren, H.L., Lu, S.Y., Li, Z.H., Chen, Q.J., Liu, Z.S., \& Liu, J.Q. (2011). An enhanced ELISA based on modified colloidal gold nanoparticles for the detection of $\mathrm{Pb}(\mathrm{II})$. Biosensors and Bioelectronics, 26, 3700-3704. DOI: 10.1016/j. bios.2011.02.008.

8. Zhou, F., Wang, M.M., Yuan, L., Cheng, Z.P., Wu, Z.Q., \& Chen, H. (2012). Sensitive sandwich ELISA based on a gold nanoparticle layer for cancer detection. Analyst, 137, 1779-1784. DOI: 10.1039/C2AN16257A.

9. He, Y.Q., Zhang, S.Q., Zhang, X.B., Zhang, X.J., Balod, M., Gurung, A., Xu, H., Zhang, X.J., \& Liu, G.D. (2011). Ultrasensitive nucleic acid biosensor based on enzyme-gold nanoparticle dual label and lateral flow strip biosensor. Biosensors and Bioelectronics, 26, 2018-2024. DOI: 10.1016/j.bios.2010.08.079.

10. Pandey, P., Singh, S.P., Arya, S.K., Gupta,V., Datta, M., Singh, S., \& Malhotra, B.D. (2007). Application of Thiolated Gold Nanoparticles for the Enhancement of Glucose Oxidase Activity. Langmuir, 23, (6) 3333-3337. DOI: 10.1021/la062901c.

11. Li, D., He, Q., Cui, Y., Duan, L., \& Li. J.B. (2007). Immobilization of glucose oxidase onto gold nanoparticles with enhanced thermostability. Biochemical and Biophysical Research Communications, 355, 488-493. DOI: 10.1016/j.bbrc.2007.01.183.

12. Chirra, H.D., Sexton, T., Biswal, D. Hersh, L.B., \& Hilt, J.Z. (2011). Catalase-coupled gold nanoparticles: Comparison between the carbodiimide and biotinstreptavidin methods. Acta Biomaterialia, 7, 2865-2872. DOI: $10.1016 /$ j.actbio.2011.01.003.

13. Haiss, W. ,Thanh, N.T.K., Aveyard, J., \& Fernig, D.G. (2007). Determination of Size and Concentration of Gold Nanoparticles from UV-Vis Spectra. Analytical Chemistry, 79, 4215-4221. DOI: 10.1021/ac0702084. 